We all want to help in the wake of such a catastrophe but, professionally, only a handful ever can; hospital staff in the main reception centres and later forensic odontologists. However, we can all help proactively, every day by keeping good and accurate records of all of our patients

\section{For the record}

The astonishing, previously unthinkable and tragic events precipitated by the London suicide bombings on 7 July cannot have failed to have made each of us think about our life, work, relations, friends, beliefs and values in new ways.

The events of the day certainly touched each of us in the BDA building very directly, as well as our colleagues in Nature Publishing, a very short distance from the King's Cross location. At that time we did not know the seriousness of the unfolding story nor had we any idea that the cause had been suicide bombers. Matters on which we contemplated one week later when we stood for two minutes in the strangely unaccustomed but moving silence of Wimpole Street

One reflection has certainly been on the rich diversity of races, peoples, faiths and cultures represented not only amongst the victims but also in the London population in particular and British society in general. This is a diversity which is also finding a strengthening reflection in the ranks of our own profession and is to be welcomed, embraced and fostered. It will only be by doing so that we can truly and properly understand and care for the patients in our charge and indeed the fellow professionals with whom we share both our work and leisure.

An agony in any such disaster, whether mediated by man's hand or natural, is the waiting period for partners, relations and friends before the confirmation that their loved ones are either safe or, tragically, deceased. The extent of the injuries, the confined sites and the need for painstaking forensic examination made this delay especially agonising in the case of the London bombings, but the principle is the same wherever identification is required.

We all want to help in the wake of such a catastrophe but, professionally, only a handful ever can; hospital staff in the main reception centres and later forensic odontologists. However, we can all help proactively, every day by keeping good and accurate records of all of our patients.

The need for positive identification, or at the very least the ability to exclude a body on the basis of personal dental records is never so urgently required or more immediate than in situations such as these. Ideally, records should be as complete as possible including chartings, notes, radiographs, clinical photographs, laboratory records, study models and so forth. In reality, of course, because life is life, the ideal is rarely achieved. Nevertheless, the fact remains that the more comprehensive the records, for which are all responsible, the greater the likelihood in the sad circumstances in which they may be required that a distraught relative or friend can know more quickly that the worst has happened. It may sound terribly callous but the reality is that we can help very directly in this way with solid evidence at a time of otherwise bewildering crisis.

As in another recent example, many of the victims of the Tsunami have either been identified wholly by dental records or had their identification aided by the corroboration of such records. However, this did also bring to light a further problem associated with modern dental materials, particularly of the "tooth coloured' variety, since the careful placing of restorations can easily be overlooked in the less than idea examination settings of a disaster scene or even a temporary mortuary. Once again it behoves us to make, update and keep careful histories and records to ensure that they are as contemporaneous as possible. Noting less common features is helpful too. An instanding tooth, a diastema, which units of a bridge form the pontics; elements not necessarily recorded routinely but which could provide the essential 'unique' identifying factor.

It would be good to be able to wish that such identification would never be necessary again. Good but unrealistic. We are a profession based on the practical and at such times the pragmatism which that engenders can be profoundly helpful. Let's keep helping positively in these ways and others.

Stephen Hancocks OBE, Editor-in Chief doi: 10.1038/sj.bdj.4812636 